$2014 / 1$

\title{
Multipurpose Alpha Mechanism for the Open-jet Wind Tunnel
}

\author{
Aleksandrs Urbahs ${ }^{1}$, Dmitrijs Titovs ${ }^{2}$, Margarita Urbaha ${ }^{3}$, Sergejs Luckinskis ${ }^{4}$, Andrejs Aleksandrovs ${ }^{5}$ \\ ${ }^{1-5}$ Institute of Aeronautics, Faculty of Transport and Mechanical Engineering, Riga Technical University
}

\begin{abstract}
The present paper deals with main problems and specifics of engineering, configuration, and considers the use of model positioning mechanism in a wind tunnel. Traditionally, this type of model positioning system is called an alpha mechanism. The main function of alpha mechanism is to adjust an angle of attack $(\alpha)$ and sliding angle $(\beta)$ for an object of aerodynamic research. This paper describes the optimal configuration of alpha mechanism for AERTI T-4 wind tunnel with appliance of CAD and CAM technologies. Also, the paper considers the possibility of improving an alpha mechanism for a wide range of aerodynamic studies.
\end{abstract}

Keywords - Aerodynamics, model positioning, wind tunnel.

\section{INTRODUCTION}

The main method of research, which determines the success of aerodynamics as a science and its wide application in many fields of technology, is the testing in wind tunnels. The wind tunnel is a physical instrument, which makes it possible to obtain a uniform rectilinear steady air flow at a given velocity in one of its elements, i.e., in the test section, where the body under test is placed. There are two main types of low-speed wind tunnels: direct impact wind tunnels and closed return wind tunnels. The AERTI T-4 wind tunnel is closed and its parameters will be characterised in the next section.

The construction and measurement complex of wind tunnel meets specific requirements that provide precise results of research. The model positioning mechanism (alpha mechanism) construction has to take into account objectives, including precise manufacturing, minimal flow influence, ergonomics and as simple design as possible etc. [1] - [6].

All of the above-mentioned requirements imply the possibility of CAD engineering methods, which provide a precise mechanism assembly. To achieve a required design and dimensions of mechanism assembly, it is possible to modify any part of mechanism using CAD software. Significant details have to be manufactured applying modern sophisticated technologies and machine-tool equipment.

Alpha mechanism designed at the Institute of Aeronautics (AERTI) of Riga Technical University fulfils all of the abovementioned requirements.

\section{CONSTRUCTION OF T-4 WIND TUNNEL}

$\mathrm{T}-4$ tunnel is an open-jet wind tunnel. The basic diagram of $\mathrm{T}-4$ wind tunnel is shown in Fig. 1.

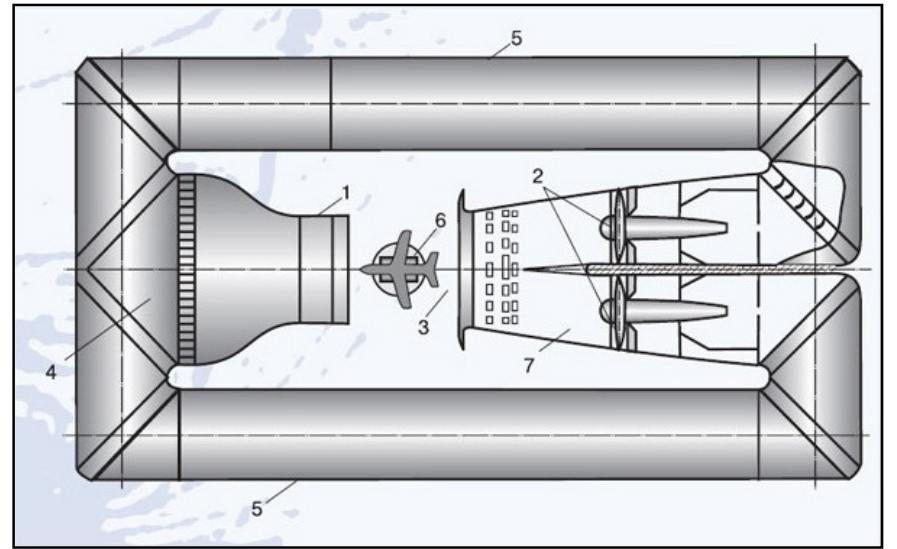

Fig. 1. The basic diagram of T-4 wind tunnel: 1 - nozzle; 2 - fans; 3 - open work area; 4 - prechamber; 5 - return passage; 6 - research model with an alpha mechanism; 7 - diffuser.

For air flow linearization there is a wind straightener with rectangle shape meshes made from wood (Fig. 2). The engine and fan section consists of two direct current motors with maximum power of $14 \mathrm{~kW}$ and two fans (Fig. 3).

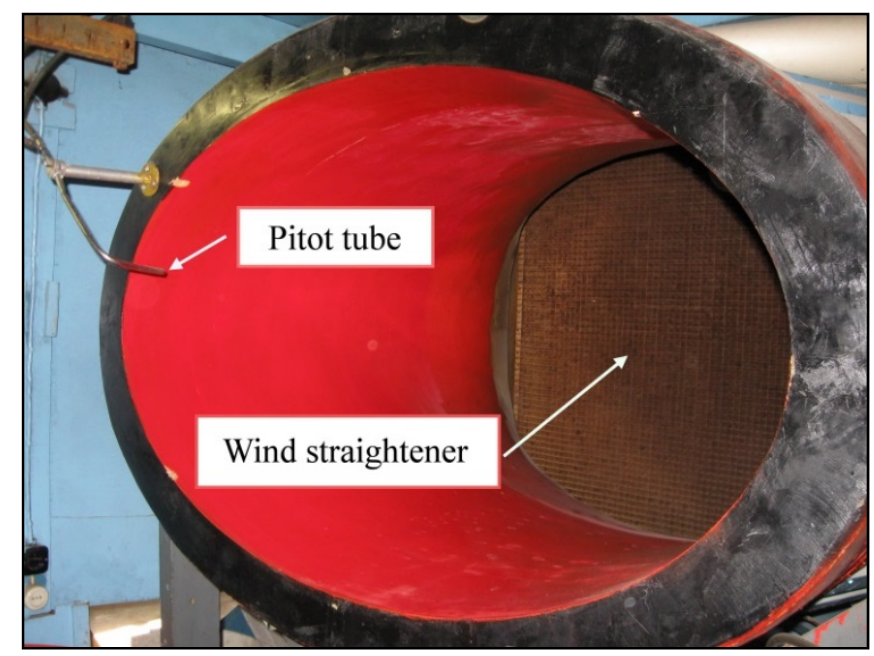

Fig. 2. Wind tunnel nozzle.

Wind flow control is performed by a variable resistor that allows varying a flow speed in motor power capabilities. Air flow velocity measurement is performed by a differential pressure method using a Pitot tube (Fig. 2) and a digital differential pressure manometer with computer software. 


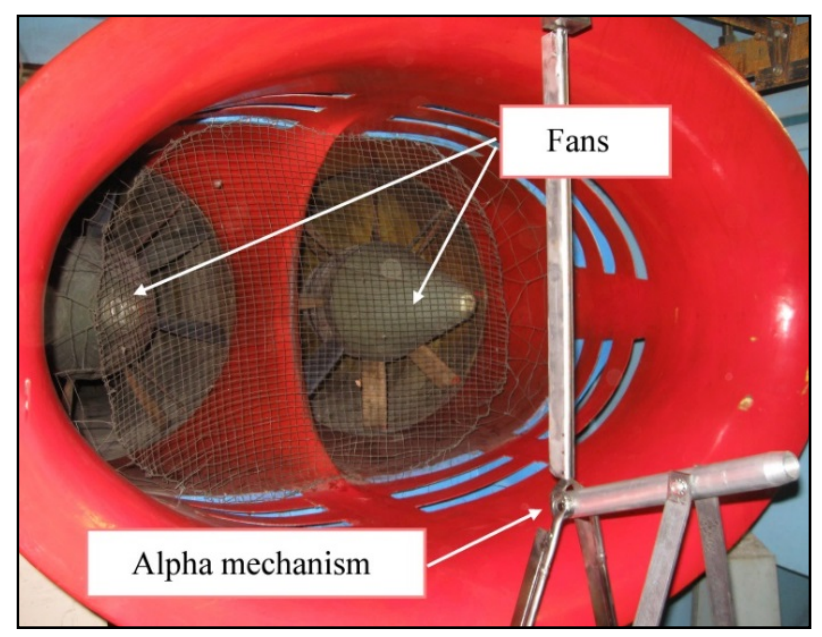

Fig. 3. Wind tunnel diffuser.

AERTI T-4 wind tunnel has an open work area with firming metal plates that have T-type connection grooves (Fig. 4). It is possible to install a wide range of experimental constructions, including an alpha mechanism and other hardware. In T-4 technical specification list (Table I) it is stated that the Reynolds number for 1 meter of any linear dimension is:

$$
R_{e}=\frac{V_{\infty} * l}{\vartheta}
$$

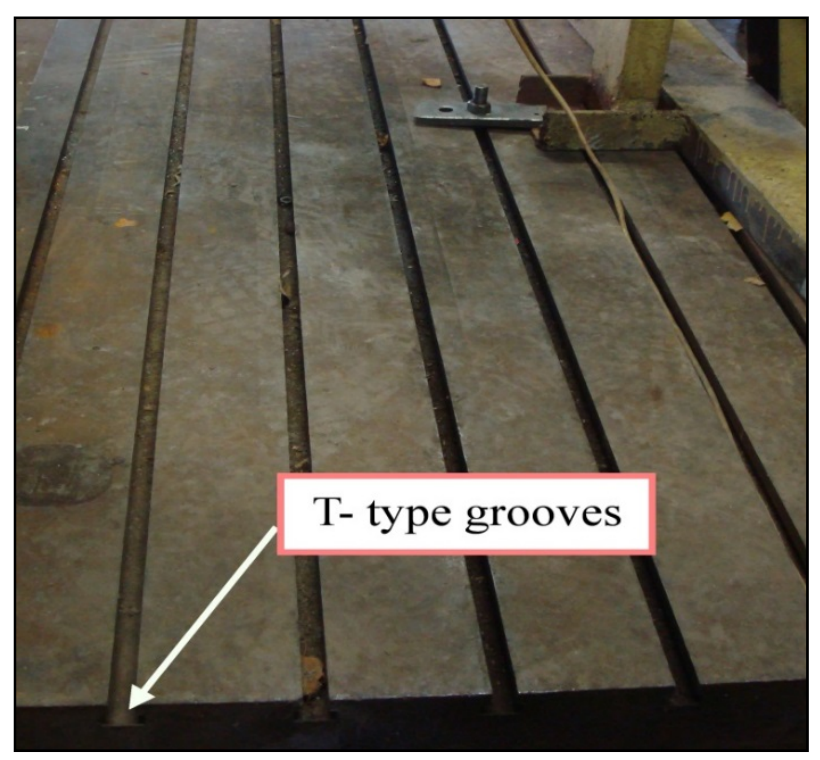

Fig. 4. Work area with strengthened metal plates.

T-4 wind tunnel is designed for aerodynamic studies of scale aircraft models. At present, it is being prepared for ESTOLAS scale model studies. For this reason, a multifunctional model positioning mechanism is designed.
TABLE I

T-4 WIND TUNNEL SPECIFICATIONS

\begin{tabular}{|l|l|}
\hline Air flow velocity (work area) & $5-30 \mathrm{~m} / \mathrm{s}$ \\
\hline Reynolds number (Re) per $1 \mathrm{~m}$ & up to $2 * 106$ \\
\hline Total pressure & atmospheric \\
\hline Dynamic pressure & up to $550 \mathrm{~Pa}$ \\
\hline Motor quantity & 2 \\
\hline Electric motor power (max) & $14 \mathrm{~kW}$ \\
\hline Number of fans & 2 \\
\hline Fan blade quantity (each) & 8 \\
\hline Work area dimensions: & $1.2 \times 0.7 \mathrm{~m}$ \\
\hline Nozzle cross section (elliptic) & $1.1 \mathrm{~m}$ \\
\hline Work area length & up to $0.8 \mathrm{~m}$ \\
\hline Dimensions of the object of research: \\
\hline Wingspan (max) & up to $1 \mathrm{~m}$ \\
\hline Fuselage length (max)
\end{tabular}

\section{BASIC REQUIREMENTS FOR ALPHA MECHANISM}

The principal task of the research was to create an alpha mechanism corresponding to the following principal requirements:

- reconcilability with internal strain gage balances of the model;

- minimal air flow influence;

- minimal interference between the model and support;

- carrying out tests in a given range of angle of attack and sliding angle;

- precision manufacturing;

- ergonomic design.

The first of the above-mentioned requirements is related to the support construction that allows connecting testing model support with alpha mechanism scheme.

The next two requirements imply that the design and shape of the support will not cause errors. Their influence on the flow pattern in the tunnel and around the tested model is considerable. In the general case, these effects are expressed in changes in the velocity and pressure distributions, which are noticed [7]:

- as changes in the average velocity in the test section, which necessitate corrections in the velocity coefficient of the tunnel;

- as changes in the pressure gradient, which create a horizontal Archimedes force affecting the drag, thus necessitating a correction in the pressure gradient;

- as changes in the flow inclination in the vertical plane near the supports, etc.

Precision manufacturing implies the application of CAM technologies and other sophisticated technologies. Alpha mechanism should be tough enough to prevent the rotational displacement of the object of research. By applying these technologies, it is possible to meet next requirements:

- accurate assembly mechanism minimal vibrations during experiments; as a result, it is possible to achieve exact experimental results; [8] 
- alpha mechanism precise work - achieving that accurate assembly rotation components get installed without swashing. As a result, joints, bearings, etc. rotate properly (without blocking).

Ergonomic design of the alpha mechanism allows installing and working around the research model quickly and without inconvenience. Also this kind of design allows placing other required hardware in a tunnel work area.

\section{Construction Specifics of Alpha Mechanism}

In wind tunnel aerodynamic studies, there are several types of model supports in a work area [9]:

- Tape-type supports;

- Wire-type supports;

- Tough link supports;

- Tough rod supports.

In case of AERTI T-4 wind tunnel, an internal strain gage balance system is used with balance-to-support connection in the rear part of model. This type of model positioning recognizes the necessity for an external mechanism with parametric variation ( $\alpha$ and $\beta$ angles).

The designed alpha mechanism fulfils the above-mentioned tasks. AERTI T-4 alpha mechanism is a tough link mechanism with a single side model connection (Fig. 5). This mechanism is placed under the wind tunnel work area for quick access to the model and other hardware.

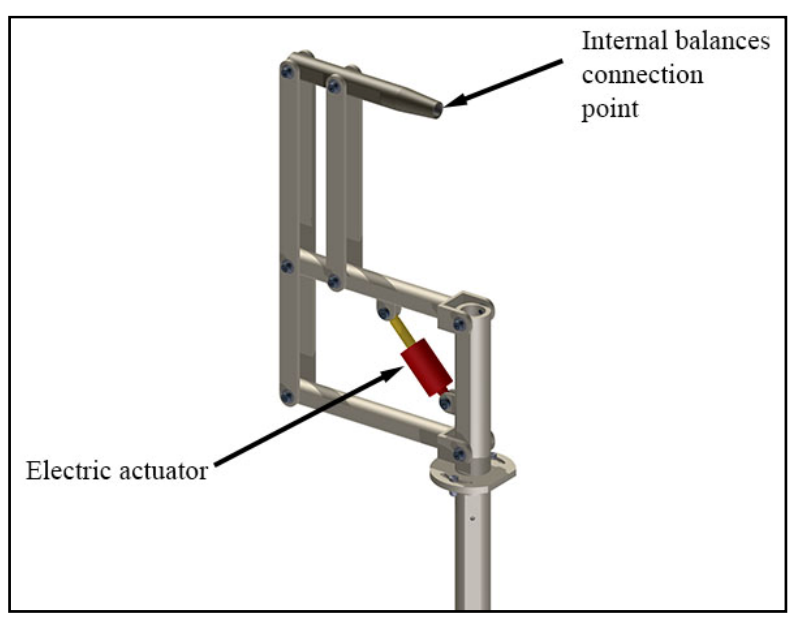

Fig. 5. CAD design of alpha mechanism.

\section{A. Construction Features}

The designed alpha mechanism is implemented by a classic parallelogram scheme (Fig. 6). The mechanism holder elements are arranged under the work area so they do not cause interference between the model and support elements.

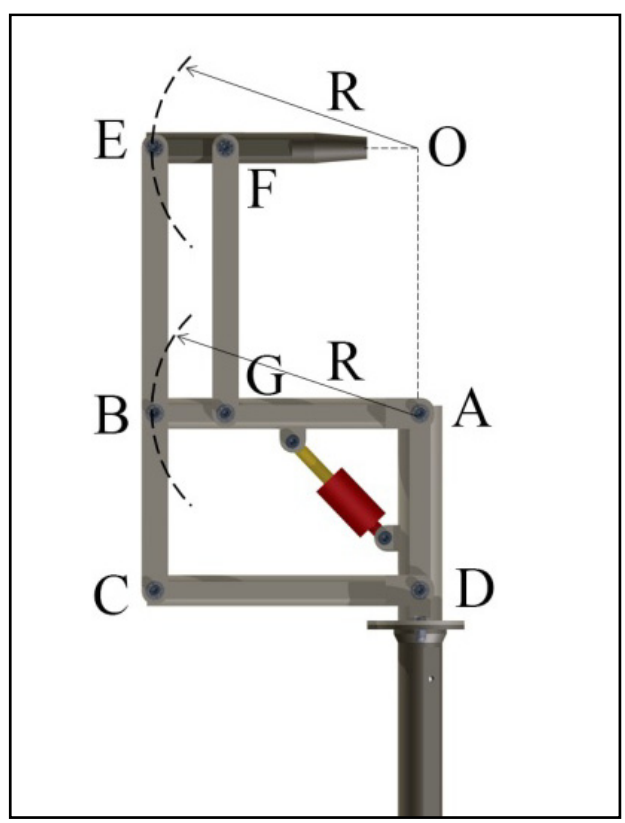

Fig. 6. Parallelogram scheme of alpha mechanism. A, B, C, D, E, F, G rotation joints with spherical bearings, $\mathrm{O}$ - centre of mass of the model.

The mechanism consists of two parallelograms (Fig. 6): 1$A B C D(A B=C D, A D=B C)$; 2- $B E F G(B G=E F, B E=F G)$. Supporting joints of parallelogram 1 are placed at $A$ and $D$ points. Arms $\mathrm{AB}$ and $\mathrm{DC}$ of parallelogram 1 are connected to bell crank $\mathrm{CBE}, \mathrm{BC}$ side of which serves as a connecting arm of $\mathrm{AB}$ and $\mathrm{DC}$ arms, but $\mathrm{BE}$ side is part of parallelogram 2. When parallelogram 2 moves, $\mathrm{B}$ and $\mathrm{C}$ joints rotate on an arc with radius $R$, wherein joint $E$ also rotates on an arc with radius $\mathrm{R}$ with centre at point $\mathrm{O}$. Thereby arms $\mathrm{DC}, \mathrm{AB}$ and $\mathrm{EO}$ change their angle around the longitudinal axis equally.

\section{B. Angle Variation}

Changing the angles is one of the main functions of alpha mechanism.

To change an angle of attack $(\alpha)$ of the model, an electric actuator is used (Fig. 5). This makes it possible to vary the angle of attack, as described previously. To measure this angle, EO arm is selected [10]. It is defined that T-4 wind tunnel air flow axial direction in the work area is parallel to the ground. This statement allows aligning the Earth's coordinate system with the coordinate system of work area. Therefore, digital clinometers are used to determine an angle between EO arm upper surface and ground level, respectively between model and air flow longitudinal axis.

Sliding angle $(\beta)$ variation is performed manually, turning the upper part of mechanism around the base element (Fig. 7). 


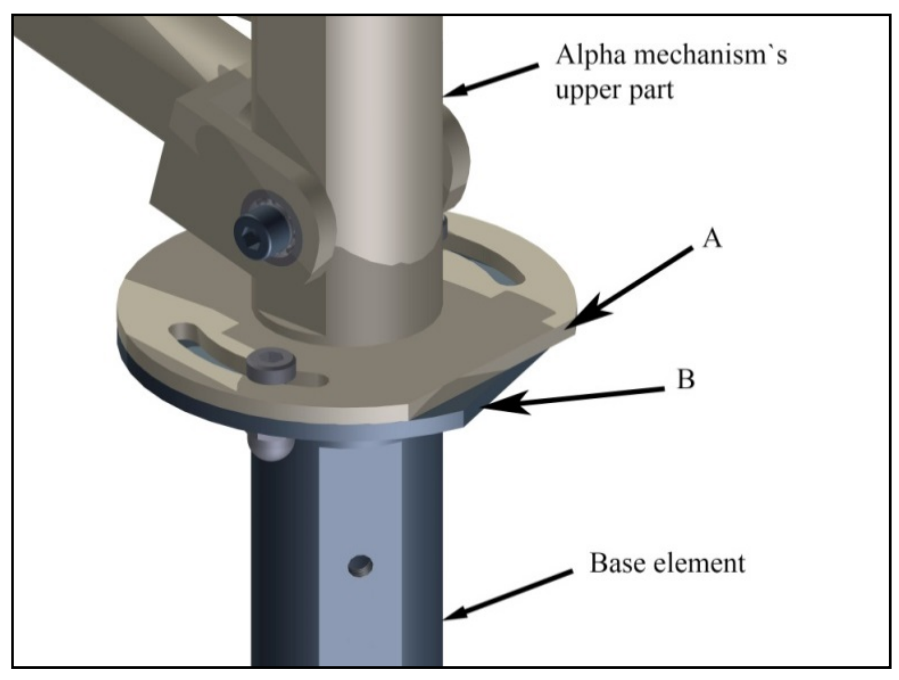

Fig. 7. Sliding angle adjustment assembly. A, B - measurement planes of sliding angle. 15-degree angle between A and B planes is defined.

Sliding angle measurement is performed with a digital angle gage (protractor). There are two planes - A and B (Fig. 7), which were milled parallel when the sliding angle was 0 degrees. To define the sliding angle number, it is necessary to measure an angle between $\mathrm{A}$ and $\mathrm{B}$ planes with an angle gage. Alpha mechanism rotational fix is performed by means of two fixing bolts on each side of the upper part of flange (Fig. 7).

\section{AlPHA MECHANISM PERSPECTIVE IMPROVEMENT}

The previously described mechanism is designed for aerodynamic studies in a static position. The designed mechanism can be improved for a wide range of aerodynamic studies, i.e.:

- the determining of rotational derivatives;

- more complex cases.

\section{A. Determining Rotational Derivatives}

The fact that various flying apparatus and objects (rockets, airplanes, missiles, etc.) undergo, during certain periods of their motion, large accelerations and considerable vibrations, while the trajectories of their centres of mass are curved, necessitates special experimental methods [7].

Modern methods permit the aerodynamic properties of bodies in a nonsteady motion to be determined experimentally [11]. This is done by considering a set of parameters, which determine the laws of nonsteady motion as a whole, and by expressing the coefficients of the aerodynamic forces and moments as functions of the coefficients of the rotational derivatives. The dimensionless coefficients of the rotational derivative of the first order (2) take into account, with accuracy sufficient in practice, the main factors caused by the nonsteady flow around the tested body [12].

$$
C_{y}=C_{y_{0}}+C_{y}^{\alpha} \alpha+C_{y}^{\dot{\alpha}} \alpha+C_{y}^{\omega_{z}}+C_{y}^{\dot{\omega}_{z}} \dot{\omega}_{z}
$$

The dimensionless force and moment coefficients can be expressed through the so-called rotational derivatives, which determine the change in the force or moment, due to the time variation of any parameter [13]. By introducing these derivatives, we can eliminate time $t$, since the motion of a body having six degrees of freedom is completely determined by the parameters given above and their time derivatives. In the most important cases the problem is simplified, since several parameters and their derivatives vanish [12].

\section{B. Complex Cases of Aerodynamic Research}

By improving the designed alpha mechanism in the future, it is possible to carry out experiments with research of dynamic influence between the model and ground surface; the change in parameters of move not only by harmonic laws (also change of parameters of move by any law).

The last capability of alpha mechanism allows implementing the real flight of the model in a wind tunnel. In this case, the signal from model internal balances processing to differential equation system of model in computer. When the signal is recalculated, it comes as a control signal of the mechanism that provides a real flight of the model.

The main problem of a back-and-forth motion is the presence of vibrations and angular distortions [14.] They are caused by guiding arms or swinging arms. Vibrations in the form of parasite inertial forces impair aerodynamic forces. This problem causes errors in experiment results. However, it is possible to use the drives on each degree of freedom in order to achieve a real flight, but it is a very expensive and difficult way [15].

The alpha mechanism improvement implies the application of a simple mechanism with a limited number of drives. It allows achieving a back-and-forth motion without the use of guiding or swinging arms, only by using repair links. For this purpose, one of the Chebyshev's mechanisms is used [16] (Fig. 8).

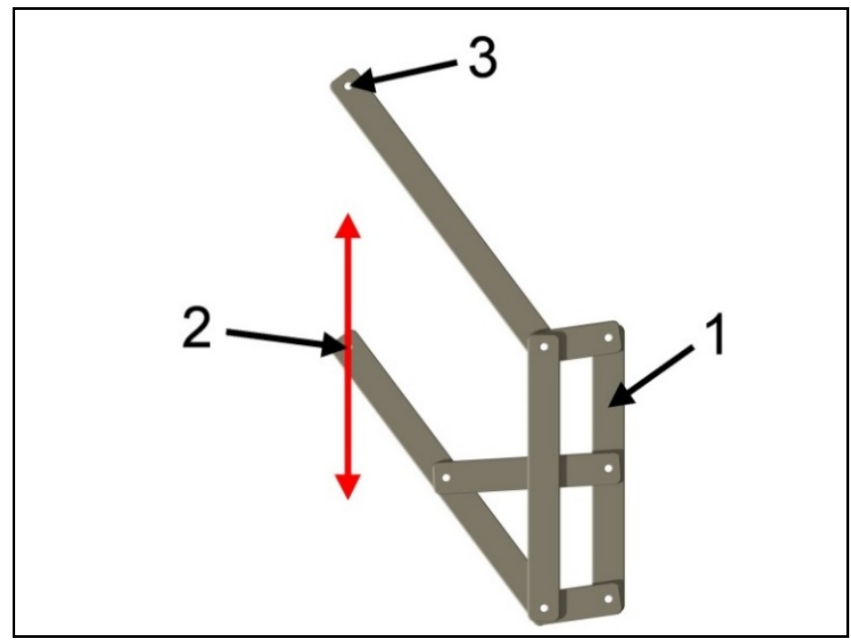

Fig. 8. The basic diagram of a back-and-forth motion mechanism. 1 - fixed arm; 2, 3 - fixing points to alpha mechanism. Red arrows show the direction of motion of the mechanism.

\section{CONCLUSIONS}

CAD model of the alpha mechanism makes it possible to modify or improve any element before manufacturing. A majority of the mechanism elements can be manufactured 
without heavy expenses [17]. This scheme of mechanism indicates a lot of preferences, i.e., reconcilability with internal strain gage balances of the model, minimal interference between the model and support, ergonomic design etc. Also there is the possibility of improving an alpha mechanism for a wide range of aerodynamic studies. Furthermore, this mechanism makes it possible to precisely predict experimental results.

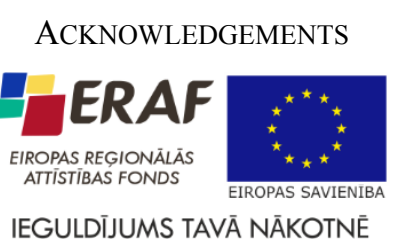

The research has been supported by the European Regional Development Fund within the project "Development of an Unmanned Aircraft System and Creation of the Industrial Prototypes of Unmanned Aerial Vehicles for Performing the Tasks of Latvian National Economy". No.2010/0256/2DP/2.1.1.1.0/10/APIA/VIAA/070.

\section{REFERENCES}

[1] A. Urbahs, M. Urbaha, V. Petrovs and A. Jakovlevs, Methods and means of the computer-aided design of unmanned aerial vehicle model: Proceeding of 2009 International Conference on Intelligent Engineering Systems (INES), pp. 211-213, Barbadosa, Barbados, 2009. http://dx.doi.org/10.1109/INES.2009.4924764

[2] A. Urbahs, V. Petrovs, A. Jakovlevs and V. Bulanovs, Specificity of constructions and perspective of use and operations in transport systems UAS micro class: Proceedings of the International Conference Transport Means, October 21-22, pp. 202-206, Kaunas, Lietuva, 2011.

[3] A.Urbahs, K. Savkovs, V. Bulanovs, V. Petrovs and A. Jakovlevs, Multipurpose unmanned aerial vehicle design: Proceedings of the International Conference Transport Means, October 23-24, pp. 30-32, Kaunas, Lietuva, 2008

[4] Y. H. Madani and M. Bensaada, "Numerical simulation and modelling of unsteady flow around an airfoil. (Aerodynamic form)," International Journal of Heat and Technology, vol. 31, issue 1, pp. 103-108, 2013.

[5] A. Vendl and H. Faßbender, "Projection-based model order reduction for steady aerodynamics Notes on Numerical Fluid Mechanics and Multidisciplinary Design," in Computational Flight Testing, Springer Berlin Heidelberg, pp. 155-166, 2013.

[6] H. Fellouah, "Aerodynamic cell design for air load measurements on high aspect ratio airfoils," SAE Technical Paper 2013-01-2286 Sep. 2013. [Online]. Available: http://papers.sae.org/ [Accessed 20.01.2014].

[7] S. M. Gorlin and I. I. Slezinger, Wind Tunnels and Their Instrumentation. Moscow: Nauka, 1964.

[8] Ricci, M. Castellani and G. Romanelli, "Multi-fidelity design of aeroelastic wing tip device," Journal of Aerospace Engineering, vol.227, pp. 1596-1604, 2013.

[9] E. L. Bedrzhicky, B. S. Dubov and A. N. Radcig, Theory and Practice of Aerodynamic Experiments. Moscow: MAI, 1990.

[10] B. T. Burchett, "Aerodynamic parameter identification for symmetric projectiles: An improved gradient based method," Aerospace Science and Technology, vol. 30, issue 1, pp. 119-127, 2013. http://dx.doi.org/10.1016/j.ast.2013.07.010

[11] M. Gennaretti, C. Testa and G. Bernardini, "An unsteady aerodynamic formulation for efficient rotor tonal noise prediction," Journal of Sound and Vibration, vol. 332, no. 25, pp. 6743-6754, 2013. http://dx.doi.org/10.1016/i.jsv.2013.07.024

[12] M. Salinas-Vázquez, W. Vicente, E. Barrios, E. Martínez, A. Palacio and A. Rodríguez, "A low-Mach number method for the numerical simulation of complex flows," Applied Mathematical Modelling, vol. 37, issue 22, pp. 9132-9146, 2013.

http://dx.doi.org/10.1016/j.apm.2013.04.004
[13] Z. Wang, Z. Liu, N. Fan and M. Guo, "Flight dynamics modelling of a small ducted fan aerial vehicle based on parameter identification," Chinese Journal of Aeronautics, vol. 26, issue 6, pp. 1439-1448, 2013. http://dx.doi.org/10.1016/j.cja.2013.10.006

[14] F. Bruzelius, D. Uystepruyst, B. Jacobson and S. Krajnović, "A simple real-time aerodynamic model for vehicles in overtaking situations," International Journal of Vehicle Systems Modelling and Testing, vol. 8, issue 3, pp. 241-259, 2013. http://dx.doi.org/10.1504/IJVSMT.2013.056037

[15] Y. Yang, Y. H. Wu, G. H. Fan, Y. K. Xu and Y. Nie, "Analysis on the influence of non-smooth surface combination arrangement on aerodynamic characteristics," Journal of Hunan University Natural Sciences, vol. 40, issue 11, pp. 40-45, 2013.

[16] I. I. Artobolevsky, Mechanism Elements. Moscow: Nauka, 1979.

[17] Z. Wang, L. Chena and S. Guo, "Numerical analysis of aerodynamic characteristics for the design of a small ducted fan aircraft," Journal of Aerospace Engineering, vol. 227, pp. 1558-1564, 2013.

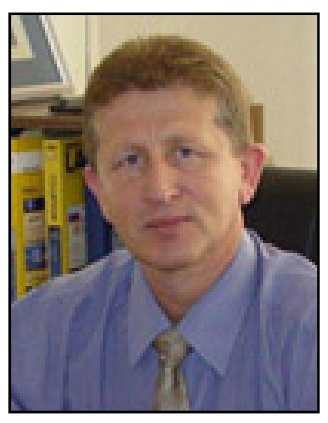

Aleksandrs Urbahs graduated from the Faculty of Mechanical Engineering, Riga Civil Aviation Engineering Institute in 1981. In 1986 he was awarded Dr.sc.ing. degree by the same faculty. In 1997 he was awarded the Dr.habil.sc.ing. degree by Riga Aviation University. In the period of 1989-1999 - Vice Dean and Dean of the Faculty of Mechanical Engineering, Riga Aviation University. Since 1999 - Full-time Professor at Riga Technical University. In the period of 1999-2012 - Head of the Institute of Transport Vehicle Technologies at Riga Technical University. Since 2012 - Head of the Institute of Aeronautics at Riga Technical University. He holds 19 patents and has published 297 scientific papers.

His fields of research: aeronautics, nanomaterials, non-destructive methods of control, structural materials, unmanned vehicles, transport systems and logistics.

Address: Institute of Aeronautics, Faculty of Transport and Mechanical Engineering, Riga Technical University, Lomonosova 1A, k-1, Riga, LV1019, Latvia.

Phone: +371 67089990

E-mail: $\underline{\text { Aleksandrs.Urbahs@rtu.lv }}$

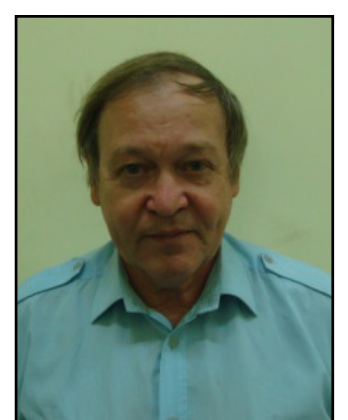

Dmitrijs Titovs graduated from the Faculty of Mechanical Engineering, Riga Civil Aviation Engineering Institute in 1969. In 2003 - Master of Science in Transportation Engineering. Since 1999 - Research Assistant at the Institute of Aviation. Since 2012 Research Assistant at the Institute of Aeronautics of Riga Technical University. His fields of research: mechanical engineering, fluid dynamics, experimental aerodynamics and science of aviation materials.

Address: Institute of Aeronautics, Faculty of Transport and Mechanical Engineering, Riga Technical University, Lomonosova 1A, k-1, Riga, LV1019, Latvia.

Phone: +37167089990

E-mail: aerti@rtu.lv, flyfil@inbox.lv

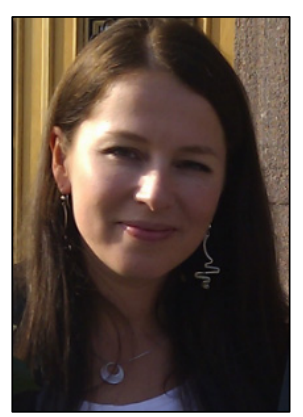

Margarita Urbaha graduated from the Faculty of Transport and Mechanical Engineering, Riga Technical University in 2011 and received the Dr.sc.ing. degree. Since 2012 she has been a Senior Researcher at the Institute of Aeronautics, Riga Technical University, and an Associate Professor at the Faculty of Transport and Mechanical Engineering, Riga Technical University. From 2010 to 2012 she was a Researcher at the Faculty of Transport and Mechanical Engineering, Riga Technical University. Since 2005 she has been a Project Manager at the Faculty of Transport and 
Mechanical Engineering, Riga Technical University. She is the author of 51 publications, 39 conference presentations.

Her fields of research: aeronautics, unmanned vehicles, nano-composite coatings, non-destructive methods of control, transport systems and logistics.

Address: Institute of Aeronautics, Faculty of Transport and Mechanical Engineering, Riga Technical University, Lomonosova 1A, k-1, Riga, LV1019, Latvia.

Phone: +37167089990

E-mail: Margarita.Urbaha@rtu.lv

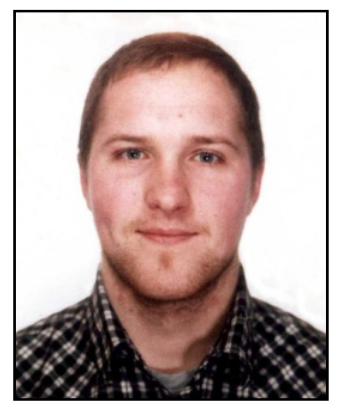

Sergejs Luckinskis since 2009 has been studying at the Institute of Aeronautics, Faculty of Transport and Mechanical Engineering, Riga Technical University. His field of specialisation is aircraft maintenance engineering. Since 2013 - Research Assistant at the Institute of Aeronautics, Riga Technical University, Latvia.

His fields of research: mechanical engineering, CAD engineering, mechanism design and aerodynamics.

Institute of Aeronautics, Faculty of Transport and Mechanical Engineering, Riga Technical University, Lomonosova 1A, k-1, Riga, LV-1019, Latvia.

Phone: +371 67089990

E-mail: Sergejs.Luckinskis@rtu.lv

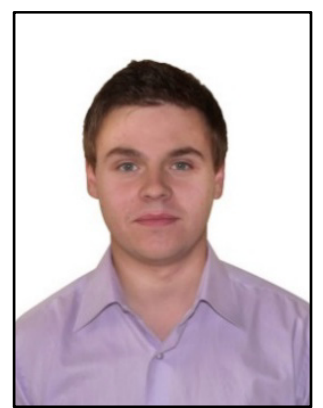

Andrejs Aleksandrovs since 2009 has been studying at the Institute of Aeronautics, Faculty of Transport and Mechanical Engineering, Riga Technical University. His field of specialisation is aircraft maintenance engineering. Since 2013 - Research Assistant at the Institute of Aeronautics, Riga Technical University, Latvia.

His fields of research: mechanical engineering, $\mathrm{CAD}$ engineering, mechanism design and hardware processing.

Institute of Aeronautics, Faculty of Transport and Mechanical Engineering, Riga Technical University, Lomonosova 1A, k-1, Riga, LV-1019, Latvia. Phone: +37167089990

E-mail: Andrejs.Aleksandrovs@rtu.lv 
Transport and Aerospace Engineering

$2014 / 1$ 